\title{
"Study of Impact of Yoga on Physiological And Biochemical Parameters in Hypertensive And Normal Subjects."
}

\author{
Dr. Sarika Sarode ${ }^{1}$, Dr. Neelam Mishra ${ }^{2,}$ Dr. Swati Tadas ${ }^{3}$ \\ ${ }^{1,2,3}$ (Department Of Physiology,, Govt. Medical College Nagpur MUHS Nashik University India
}

\begin{abstract}
Stress is found to be an important factor in the etiology or precipitation of hypertension. Yoga controls the stress. In the present study we aim to study the degree of effect that yoga brings in normal subjects as compared to hypertensive subjects, in terms of various physiological cardio-respiratory parameters and biochemical parameters.

Type of trial: - This was the prospective; follow up, multiple comparison groups, non-cross over 90 days trial. Study design:- The study included three different groups. The control and the study group underwent yogic session daily of 1.5-hour duration for a total period of 90 days. Physiological parameters studied at the beginning of the study and thereafter, every 30 days, till the end of the study i.e. 90 days were, Pulse rate, Respiratory rate and Blood pressure. Biochemical parameters assessed at the start and completion of the study were Serum total cholesterol, Serum triglyceride, Serum HDL-cholesterol, Serum LDL cholesterol . Statistically significant decrease was observed in all the physiological and biochemical parameters in all the study groups. It was concluded that in hypertensive subjects whether newly diagnosed or already diagnosed, there is restoration of the altered parameters towards normal.
\end{abstract}

Keywords: Yoga ,Hypertension,Lipid profile

\section{Introduction}

Hypertension is the major risk factor for many non-communicable diseases like cardiovascular diseases, stroke, renal failure and diabetes mellitus. ${ }^{1,2}$ Apart from the developed countries with aging population, now the developing countries like India with a younger population are showing rising trends in the prevalence of hypertension.Hypertension is estimated to cause $4.5 \%$ of current global diseases ${ }^{4}$ and about one billion people suffer from it worldwide. ${ }^{5}$ Recent data suggest that hypertensive persons are more predisposed to the development of diabetes than the normotensive persons. Stress is found to be an important factor in the etiology or precipitation of these conditions. Therefore, along with many other diseases hypertension and diabetes are also included under psychosomatic diseases. Lifestyle modifications are to be seriously considered as an adjunct to the drug interventions. ${ }^{8}$ Yoga influences the body as well as controls the stress (external or internal) in the individual, promotes well being, improves quality of life and its safety profile is excellent. We aim to study the degree of effect that yoga brings in normal subjects as compared to hypertensive subjects, in terms of various physiological cardio-respiratory parameters and biochemical parameters.

\section{Materials And Methods}

Setting: - Present trial was carried out in the Department of Physiology Government Medical College and Hospital (GMCH), Nagpur, India and the biochemical analysis was done in the laboratory of department of Biochemistry, GMCH, Nagpur. The subjects were trained in yogic practices at Shree Janaradan Swami Yogabhyasi Mandal, Ramnagar, Nagpur.

Type of trial: - This was the prospective; follow up, multiple comparison groups, non-cross over 90 days trial.

Planned Study population: -

Control group fulfilling the following criteria: -

1. Normal healthy adult volunteers more than 40 years of age, of both genders.

2. Non-smoker, non-alcoholic.

3. Not doing yoga previously.

4. Not on any medication.

A. Inclusion criteria for study group;-

1. Subjects above 40 yrs of age of both the genders.

2. Subjects having essential hypertension which included, 
Subjects with newly diagnosed Stage-1 hypertension and are not on any medication.

Subjects with hypertension diagnosed within last 5 yrs and are on medication.

3. Not doing Yoga previously.

4. Subjects who are nonalcoholic and nonsmokers.

\section{Exclusion criteria: -}

1. Subjects with Stage-2 hypertension.

2. Subjects with hypertension with cardiovascular or cerebral complications.

3. Subjects with secondary hypertension.

4. Subjects already practicing yoga.

5. Subjects on medication altering lipid profile.

6. Pregnant women.

\section{B. Ethics clearance and informed consent: -}

Study was approved by institutional ethics committee. Informed consent was obtained from the subjects after explaining the study design.

Sample size: - The sample size was calculated by the statistician on the basis of previous study.

Study design: -

The study included three different groups.

Group I - Normal healthy controls.

Group II - Subjects with newly diagnosed Stage-1 hypertension and are not on any medication.

Group III - Subjects with hypertension diagnosed within last 5 yrs and are on medication

\section{Planned intervention: -}

The control and the study group underwent yogic session daily of 1.5-hour duration from 6 to $7.30 \mathrm{am}$ in the morning for a total period of 90 days. The session started with Awayawa-dhyana and a short prayer followed by various asanas, pranayama, meditation and ended with a short prayer.

Physiological Parameters assessed were,

Pulse rate, Respiratory rate and Blood pressure

Biochemical Parameters estimated were: -

* Serum total cholesterol by enzymatic method.

* Serum triglyceride by enzymatic method.

* Serum HDL-cholesterol by phosphotungstate precipitation followed by enzymatic method.

* Serum LDL cholesterol by Friedwald formula

\section{Statistical analysis:}

Continuous variables were presented as mean $\pm \mathrm{SD}$. The continuous variables were compared at different time intervals within the group and also between the groups. Statistical analysis of data was performed either using a one way analysis of variance (ANOVA) followed by Bonferroni's multiple comparison test or unpaired t-test for continuous variables. Two tailed $p$ value of less than 0.05 was judged statistically significant. Statistical calculations were done by using statistical software STATA version 8.0.

\section{Results And Observations}

Table 1: Group I- Change in physiological parameters.

\begin{tabular}{|c|c|c|c|c|c|}
\hline \multirow{2}{*}{ Parameters } & \multicolumn{4}{|l|}{ II. DAY } & \multirow{2}{*}{$\begin{array}{l}\mathbf{p} \\
\text { ANOVA }\end{array}$} \\
\hline & 0 & 30 & 60 & 90 & \\
\hline A. $\quad P R$ & $70.8 \pm 3.23$ & $70.5 \pm 3.91$ & $70.1 \pm 3.13$ & $68.3 \pm 3.49^{* *}$ & $<0.05$ \\
\hline B. $\quad R R$ & $14.56 \pm 1.92$ & $14.06 \pm 2.16$ & $13.4 \pm 1.71^{* *}$ & $12.86 \pm 2.55^{* * *}$ & $<0.05$ \\
\hline SBP & $116.67 \pm 2.42$ & $115.06 \pm 2.86^{* *}$ & $113.86 \pm 2.77^{* * *}$ & $111.6 \pm 2.57^{* * *}$ & $<0.001$ \\
\hline DBP & $77.06 \pm 2.91$ & $76.8 \pm 1.94$ & $75.06 \pm 2.21^{* * *}$ & $74.6 \pm 2.47^{* * *}$ & $<0.001$ \\
\hline MBP & $90.27 \pm 2.05$ & $89.55 \pm 1.76$ & $87.99 \pm 1.79^{* * * *}$ & $86.93 \pm 2.11^{* * * *}$ & $<0.001$ \\
\hline PP & $39.6 \pm 3.91$ & $38.27 \pm 3.09$ & $38.8 \pm 3.42$ & $37.0 \pm 2.81^{* * *}$ & $<0.05$ \\
\hline
\end{tabular}

Values expressed in mean $\pm \mathrm{SD}$ of per min values for $\mathrm{PR}$ and $\mathrm{RR}$,

Values expressed in mean \pm SD of $\mathrm{mm}$ of $\mathrm{Hg}$ for SBP, DBP, MBP and PP, 
$* * \mathrm{p}<0.01 \mathrm{Vs} \mathrm{O}$ value,

$* * * \mathrm{p}<0.001 \mathrm{Vs} \mathrm{O}$ values,

p as determined by one way ANOVA with Bonferroni's multiple comparison post test,

$\mathrm{PR}=\mathrm{Pulse}$ Pressure, $\mathrm{RR}=$ Respiratory rate, $\mathrm{SBP}=$ Systolic Blood Pressure, DBP=Diastolic Blood Pressure, $\mathrm{MBP}=$ Mean Blood pressure, $\mathrm{PP}=\mathrm{Pulse}$ pressure,

Table 2: Group II- Change in physiological parameters.

\begin{tabular}{|c|c|c|c|c|c|}
\hline \multirow{2}{*}{ Parameters } & \multicolumn{4}{|l|}{ Day } & \multirow{2}{*}{ p Value } \\
\hline & 0 & 30 & 60 & 90 & \\
\hline C. $P R$ & $76.78 \pm 4.27$ & $75.82 \pm 3.49$ & $75.25 \pm 2.82^{*}$ & $73.75 \pm 3.43^{* *}$ & $<0.05$ \\
\hline D. $R R$ & $17.14 \pm 2.43$ & $16.53 \pm 2.71$ & $15.60 \pm 2.16^{* *}$ & $15.21 \pm 3.40^{* *}$ & $<0.05$ \\
\hline SBP & $147.92 \pm 6.83$ & $140.57 \pm 6.71^{* *}$ & ${ }_{*} 35.29 \pm 6.31^{* *}$ & $128.42 \pm 6.89^{* * *}$ & $<0.001$ \\
\hline DBP & $92.57 \pm 5.60$ & $91.28 \pm 5.42^{*}$ & $88.5 \pm 4.37^{* * *}$ & $83.92 \pm 3.79^{* * *}$ & $<0.001$ \\
\hline MBP & $111.02 \pm 5.03$ & $107.71 \pm 4.73^{* *}$ & $104.09 \pm 4.12^{* *}$ & $98.76 \pm 3.58^{* * *}$ & $<0.001$ \\
\hline PP & $55.35 \pm 7.05$ & $49.28 \pm 7.40^{* * *}$ & $46.78 \pm 6.35^{* * *}$ & $44.5 \pm 7.51^{* * *}$ & $<0.001$ \\
\hline
\end{tabular}

Values expressed in mean \pm SD of per min values for PR and RR,

Values expressed in mean \pm SD of $\mathrm{mm}$ of $\mathrm{Hg}$ for SBP, DBP, MBP and PP,

$* \mathrm{p}<0.05 \mathrm{Vs}$ O Value,

$* * \mathrm{p}<0.01 \mathrm{Vs} \mathrm{O}$ value,

$* * * \mathrm{p}<0.001 \mathrm{Vs} \mathrm{O}$ values,

$\mathrm{p}$ as determined by one way ANOVA with Bonferroni's multiple comparison post test,

$\mathrm{PR}=$ Pulse Pressure, $\mathrm{RR}=$ Respiratory rate, $\mathrm{SBP}=$ Systolic Blood Pressure, DBP=Diastolic Blood Pressure, $\mathrm{MBP}=$ Mean Blood pressure, $\mathrm{PP}=\mathrm{Pulse}$ pressure,

Table 3: Group III- Change in physiological parameters.

\begin{tabular}{|c|c|c|c|c|c|}
\hline \multirow{2}{*}{ Parameters } & \multicolumn{4}{|l|}{ Day } & \multirow{2}{*}{ p ANOVA } \\
\hline & 0 & 30 & 60 & 90 & \\
\hline E. $P R$ & $78.03 \pm 3.09$ & $77.63 \pm 3.2$ & $75.57 \pm 3.64^{*}$ & $74.96 \pm 5.54^{* * *}$ & $<0.01$ \\
\hline F. $\quad R R$ & $16.33 \pm 2.96$ & $15.45 \pm 2.45$ & $15.09 \pm 1.97^{*}$ & $14.27 \pm 3.66^{* *}$ & $<0.05$ \\
\hline SBP & $138.36 \pm 8.70$ & $135.33 \pm 9.03^{* *}$ & $131.15 \pm 6.10^{* * *}$ & $125.39 \pm 5.51^{* * *}$ & $<0.001$ \\
\hline DBP & $84.61 \pm 3.40$ & $83.15 \pm 3.31^{* *}$ & $81.15 \pm 3.43^{* * *}$ & $78.42 \pm 4.09^{* * * *}$ & $<0.001$ \\
\hline MBP & $102.52 \pm 4.29$ & $100.54 \pm 4.15^{* * *}$ & $97.82 \pm 3.28^{* * *}$ & $94.36 \pm 3.18^{* * *}$ & $<0.001$ \\
\hline PP & $53.75 \pm 8.10$ & $52.18 \pm 8.83$ & $50.00 \pm 6.53^{* *}$ & $46.54 \pm 7.09^{* * *}$ & $<0.01$ \\
\hline
\end{tabular}

Values expressed in mean \pm SD of per min values for PR and RR,

Values expressed in mean \pm SD of $\mathrm{mm}$ of $\mathrm{Hg}$ for SBP, DBP, MBP and PP,

$* \mathrm{p}<0.05 \mathrm{Vs}$ O Value, ${ }^{*} \mathrm{p}<<0.01 \mathrm{Vs} \mathrm{O}$ value, $* * * \mathrm{p}<0.001 \mathrm{Vs} \mathrm{O}$ values, $\mathrm{p}$ as determined by one way ANOVA with Bonferroni's multiple comparison post test,

$\mathrm{PR}=\mathrm{Pulse}$ Pressure, $\mathrm{RR}=$ Respiratory rate, $\mathrm{SBP}=$ Systolic Blood Pressure, DBP=Diastolic Blood Pressure, $\mathrm{MBP}=$ Mean Blood pressure, $\mathrm{PP}=\mathrm{Pulse}$ pressure,

Table 4: Group 1 Change in biochemical parameters.

\begin{tabular}{|c|c|c|c|}
\hline \multirow{2}{*}{ Parameters } & \multicolumn{2}{|l|}{ Day } & \multirow{2}{*}{$\begin{array}{l}\mathbf{p} \\
\text { ANOVA }\end{array}$} \\
\hline & 0 & 90 & \\
\hline$T C$ & $150.76 \pm 19.9$ & $146.4 \pm 16.93$ & $<0.01$ \\
\hline TG & $93.06 \pm 17.92$ & $89.63 \pm 17.78$ & $<0.05$ \\
\hline HDL & $52.96 \pm 7.42$ & $55.3 \pm 7.75$ & $>0.05$ \\
\hline LDL & $79.18 \pm 17.24$ & $73.17 \pm 14.76$ & $<0.01$ \\
\hline VLDL & $18.61 \pm 3.58$ & $17.92 \pm 3.57$ & $<0.05$ \\
\hline TC/HDL & $2.89 \pm 0.48$ & $2.68 \pm 0.37$ & $<0.01$ \\
\hline LDL/HDL & $1.53 \pm 0.43$ & $1.35 \pm 0.34$ & $<0.01$ \\
\hline FBS & $92.76 \pm 11.75$ & $87.93 \pm 9.62$ & $<0.05$ \\
\hline PMBS & $118.3 \pm 17.06$ & $110.73 \pm 12.03$ & $<0.05$ \\
\hline
\end{tabular}

Values expressed in mean \pm SD of mg/dl for TC, TG, HDL, LDL, VLDL, FBS and PMBS, Values expressed in mean \pm SD of ratio for TC/HDL, LDL/HDL, 
$\mathrm{P}<0.05$ is considered as significant,

$\mathrm{p}$ as determined by paired ' $\mathrm{t}$ ' test. $\mathrm{TC}=$ total cholesterol, $\mathrm{TG}=$ triglycerides, $\mathrm{HDL}=$ high density lipoprotein, $\mathrm{LDL}=$ low density lipoprotein, $\mathrm{VLDL}=$ very low density lipoprotein, $\mathrm{FBS}=$ fasting blood sugar, $\mathrm{PMBS}=$ post meal blood sugar.

Table 5: Group II Change i

\begin{tabular}{|l|l|l|l|}
\hline \multicolumn{1}{|c|}{ Parameters } & \multicolumn{2}{|l|}{ Day } & P \\
\cline { 2 - 3 } & $\mathbf{0}$ & $\mathbf{9 0}$ & ANOVA \\
\hline$b)$ & $180.28 \pm 32.56$ & $172.07 \pm 25.82$ & $<0.05$ \\
\hline TG & $121.71 \pm 45.49$ & $113.32 \pm 37.56$ & $<0.05$ \\
\hline HDL & $44.60 \pm 9.70$ & $49.71 \pm 13.64$ & $>0.05$ \\
\hline LDL & $111.33 \pm 38.06$ & $99.69 \pm 33.21$ & $<0.01$ \\
\hline VLDL & $24.32 \pm 9.09$ & $22.66 \pm 7.57$ & $<0.05$ \\
\hline TC/HDL & $4.23 \pm 1.17$ & $3.67 \pm 0.96$ & $<0.01$ \\
\hline LDL/HDL & $2.65 \pm 1.12$ & $2.17 \pm 0.90$ & $<0.01$ \\
\hline FBS & $94.71 \pm 9.54$ & $89.92 \pm 7.40$ & $<0.05$ \\
\hline PMBS & $121.43 \pm 17.78$ & $112.14 \pm 17.07$ & $<0.05$ \\
\hline
\end{tabular}

$\mathrm{n}$ biochemical parameters.

Values expressed in mean \pm SD of mg/dl for TC, TG, HDL, LDL, VLDL, FBS and PMBS,

Values expressed in mean \pm SD of ratio for TC/HDL, LDL/HDL,

$\mathrm{P}<0.05$ is considered as significant,

$\mathrm{p}$ as determined by paired ' $\mathrm{t}$ ' test.

$\mathrm{TC}=$ total cholesterol, $\mathrm{TG}=$ triglycerides, $\mathrm{HDL}=$ high density lipoprotein, $\mathrm{LDL}=$ low density lipoprotein, VLDL=very low density lipoprotein, FBS= fasting blood sugar, PMBS= post meal blood sugar.

Table 6: Group III Change in biochemical parameters.

\begin{tabular}{|c|c|c|c|c|}
\hline \multirow{2}{*}{\multicolumn{2}{|c|}{ Parameters }} & \multicolumn{2}{|l|}{ Day } & \multirow{2}{*}{$\begin{array}{l}\mathbf{P} \\
\text { ANOVA }\end{array}$} \\
\hline & & 0 & 90 & \\
\hline c) & $T C$ & $194.2 \pm 44.24$ & $184.4 \pm 35.29$ & $<0.05$ \\
\hline TG & & $133.9 \pm 34.39$ & $120.7 \pm 23.12$ & $<0.01$ \\
\hline HDL & & $46.24 \pm 10.51$ & $52.18 \pm 11.85$ & $<0.05$ \\
\hline LDL & & $121.2 \pm 41.79$ & $108.0 \pm 31.93$ & $<0.01$ \\
\hline VLDL & & $26.78 \pm 6.88$ & $24.13 \pm 4.62$ & $<0.01$ \\
\hline TC/HDL & & $4.38 \pm 1.34$ & $3.68 \pm 0.96$ & $<0.01$ \\
\hline LDL/HDL & & $2.77 \pm 1.22$ & $2.18 \pm 0.84$ & $<0.01$ \\
\hline FBS & & $98.45 \pm 12.43$ & $92.24 \pm 9.98$ & $<0.05$ \\
\hline PMBS & & $119.63 \pm 14.55$ & $111.78 \pm 12.88$ & $<0.01$ \\
\hline
\end{tabular}

Values expressed in mean \pm SD of mg/dl for TC, TG, HDL, LDL, VLDL, FBS and PMBS,

Values expressed in mean \pm SD of ratio for TC/HDL, LDL/HDL,

$\mathrm{P}<0.05$ is considered as significant,

$\mathrm{p}$ as determined by paired ' $\mathrm{t}$ ' test.

$\mathrm{TC}=$ total cholesterol, $\mathrm{TG}=$ triglycerides, HDL=high density lipoprotein, $\mathrm{LDL}=$ low density lipoprotein, VLDL=very low density lipoprotein, FBS= fasting blood sugar, PMBS= post meal blood sugar.

\section{Results And Observations}

In the present study it was found that the pulse rate was decreased significantly $(\mathrm{p}<0.05)$ at 60 days in Group II, III .Also pulse rate was significantly reduced at 90 days in group I ,II, and group III $(\mathrm{p}<0.001)$. [Table 1-3] RR decreased significantly at 60 day in group I, and II with $\mathrm{p}<0.01$ while in group III with $\mathrm{p}<0.05$. This significant decrease continued at 90 days also with group II and III $(<0.01)$ and group I $(\mathrm{p}<0.001)$. [Table 1-3]

Present study showed significant decrease in SBP beginning at 30 days. And it was very highly significant $(\mathrm{p}<0.001)$ in-group II as compared to others. At 60 and 90 days all the groups had highly significant decrease in SBP $(\mathrm{p}<0.001)$. [Table 1-3]

Present study showed significant decrease in DBP at 30 days in Group II and III $(\mathrm{p}<0.05, \mathrm{p}<0.01$ respectively) while at 60 and 90 days the entire groups showed significant decrease. [Table 1-3]

Mean blood pressure showed significant decrease at 30 days in groups II, III $(\mathrm{p}<0.001)$ and at 60 days in Group I ( $\mathrm{p}<0.001)$ compared to day 0 values. [Table 1-3] 
In our study it was found that only Group II had significant $(\mathrm{p}<0.001)$ reduction in PP at 30 days. The decrease in PP was significant in Group II and III ( $p<0.001$ and $p<0.01$ respectively) at 60 days. At the end of the trial, all the groups had, very highly significant decrease in PP with $\mathrm{p}<0.001$. [Table 1-3]

In present study decrease in the total cholesterol was found in all the groups at 90 days. The decrease was significant $(\mathrm{p}<0.05)$ for Group II and III while it was highly significant in Group I $(\mathrm{p}<0.01)$. [Table 4-6]

After yoga, at 90 days, the reduction in the serum triglycerides levels was found in all the groups in the present study. The decrease was significant $(\mathrm{p}<0.05)$ in Group I and II, while it was highly significant $(\mathrm{p}<0.01)$ in Group III [Table 4-6]

After 90 days of yogic practices significant $(p<0.05)$ increase in the HDL level was found in Group III. Increasing levels of HDL were observed in Group II and I though the changes were not significant at 90 days. [Table 4-6]

Present study found highly significant reduction in the LDL levels after yoga therapy in Group I, II and III $(\mathrm{p}<0.01)$ [Table 4-6]

Study showed changes in the VLDL levels parallel to TG levels in all the three groups. The decrease was significant in Group I and II ( $p<0.05)$ and was highly significant in Group III $(p<0.01)$. [Table 4-6]

The present study found higher TC/HDL ratio and LDL/HDL ratio in Group II, III as compared to Group I at baseline. Ninety days of yoga therapy resulted in significant reduction $(\mathrm{p}<0.01)$ in Group I, II and III [Table 4-6]

\section{Discussion}

The present study was aimed to assess the extent of impact of yogic practices in persons above 40 years having different physiological conditions i.e. in healthy subjects with normal physiology and in hypertensive subjects i.e. with altered physiology.

Physiological parameters were studied at the beginning of the study and thereafter, every 30 days, till the end of the study i.e. 90 days. Biochemical parameters were assessed at the start and completion of the study. In the present study the significant decrease in pulse rate started at 60 days in Group II and III while at 90 days in group I. [Table 1-3]. Many studies depicted changes in pulse rate with yogic practices. ${ }^{10,11,12,13,14}$. The decrease in pulse rate was significant except in the study of Nayar HS. Yoga brings about the behavioural change, which is the cortical influence along with influence of limbic system on hypothalamus. ${ }^{15}$ The result is increased parasympathetic tone and reduced sympathetic tone. The pulse rate decreases mainly because of increased parasympathetic tone. ${ }^{16,17}$ Yoga by modifying the stage of anxiety reduces stress induced sympathetic overactivity. ${ }^{17,18}$

It was found in the present study that yoga causes reduction in the respiratory rate (RR). RR decreased significantly at 60 day in all the groups. This significant decrease continued at 90 days also. [Table 1-3] . No significant difference of change in the respiratory rate and pulse rate was found in between the groups. [Table 79]. The decrease in the respiratory rate shows the shift to a relative parasympathetic dominance from earlier sympathetic dominance. ${ }^{10}$ The decrease may also be due to the psychosomatic relaxation caused by the yogic practices.

Significant decrease in SBP was observed at the beginning at 30 days in all the groups and it was very highly significant in-group II. While at 60 and 90 days all the groups showed very highly significant decrease in SBP. [Table 1-3] . The change in the SBP from baseline at 30, 60 and 90 days is highest in group II than group I and III Thus it can be said that yoga is more beneficial in reducing the SBP if given earlier in the course of disease. This may be because the SBP, which is prone for fluctuations due to various arousal responses, undergoes fewer alterations after yoga, as yoga decreases the sympathetic arousal response and stress induced reactions. Our findings are in consistence with many studies. ${ }^{20,10,11,12,13,14}$. Dhameja et al ,concluded that, yoga decreases blood pressure and oxidative stress in patents with hypertension. ${ }^{21}$ Jayaram et al and Mohd Noor jahan begum et al observed significant decrease in SBP and DBP in subjects who have practiced yoga along with pranayam technique 22,23

Yoga brings about behavioral change through its effect on hypothalamus causing increase in the parasympathetic tone and reduction in the sympathetic tone which was also confirmed by Singh $\mathbf{S}$ et $\mathbf{a l}^{14}$. Dorsomedial hypothalamic nucleus plays a key role in integrating the cardiovascular response to stress. ${ }^{20}$ The increase in the baroreceptor sensitivity after yoga in hypertensive subjects also shows the predominance of parasympathetic activity. There is progressive attenuation of sympatho-adrenal axis and renin-angiotensin activity after yoga. ${ }^{24}$ It was suggested that insulin resistance with reactive hyperinsulinemia might lead to hypertension through mechanisms like increased sympathetic nervous system activity, enhancement of sodium retention, alteration of cation transport, hypertrophy of vascular smooth muscle cells and stimulation of reninangiotensin system. ${ }^{25,26}$ The reduction in SBP may be due to decrease in the insulin resistance and associated hyperinsulinemia. 
In the present study significant decrease in DBP started at 30 days in Group II, III and at 60 in Group I which further continued till the completion of study. [Table 1-3]. Others studies are also having findings similar to us,20,10,11,12,13,14 Yoga was found to reduce the DBP along with the SBP. It is because of the relaxation effect of yoga which decreases the sympathetic tone which in turn reduces the peripheral resistance and thereby the DBP. ${ }^{19}$ This may be due to the cognitive restructuring with sensory and motor attenuation leading to decreased arousal to external stimuli. ${ }^{27}$ The decrease in the DBP after yoga in our study can be beneficial as DBP is also related to the risk of cardiac events in hypertensive subjects. ${ }^{28}$

Mean blood pressure (MBP) was significantly decreased at 30 days in groups II, III and at 60 days in Group I compared to day 0 values. [Table 1-3].The decrease in the mean blood pressure was due to decrease in the DBP along with decrease in the pulse pressure. Our results were in accordance with Madanmohan et $\mathbf{a l}^{12}$ And Vijayalakshmi et $\mathbf{a l}^{13}$ also found significant $(\mathrm{p}<0.001)$ reduction in MBP in hypertensive subjects after yoga training.

The reduction in pulse pressure (PP) was seen at different time periods in different groups. The decrease started at 30 days in Group II, at 60 days in Group III and continued at 90 days. The decrease in PP may be due to more reduction in the SBP than the DBP. While Madanmohan et al ${ }^{12}$ stated non significant change in PP in normal healthy volunteers. Vijayalakshmi et al $^{13}$ found significant $(p<0.0001)$ reduction in the PP in hypertensive subjects after yoga training. Pulse pressure which is the pulsatile blood pressure index is an independent risk factor for cardiac events in essential hypertension. ${ }^{28,29}$ The greater reduction in PP in Group II may indicate the salutary effect of yoga in the earlier phases of the course of the disease.

\section{Biochemical Parameters: -}

Various parameters included in lipid profile are associated with the risk of cardiac events in subjects of essential hypertension. ${ }^{30}$ After yogic practices for 90 days the lipid profile shifted toward favourable site in all the groups i.e. there was significant decrease in total cholesterol (TC), Triglycerides (TG), low density lipoproteins (LDL), very low density lipoprotein (VLDL) while in Group III there was significant increase in high density lipoproteins (HDL). [Table 4-6]

Variable effects of yoga on lipid profile were observed in many studies. Yoga decreased serum cholesterol levels in normal and hypertensive subjects in our study. In accordance to our findings Khare et $\mathbf{~ a l}^{31}$ found significant $(\mathrm{p}<0.005)$ decrease in diabetic subjects after yoga. Damodaran et al ${ }^{10}$ and Bhagal et al ${ }^{31}$ found decrease in the cholesterol and TG levels after yoga in hypertensive subjects and meditation in normal subjects respectively but the results were not significant.

Increased levels of plasma cortisol and blood glucose and increased levels of atherogenic lipids, serum TGs and TC occur in essential hypertension. ${ }^{33}$ This is due to the response of hypothalamo-pituitary axis to stress. As yoga causes balance between the components of the autonomic nervous system, the exaggerated response of the hypothalamus and the limbic system to stress is blunted leading to favorable change in the cholesterol levels.

Regular exercise reduces plasma total and unesterified cholesterol and adipose tissue phospholipids. This may be due to increased plasma lecithin-cholesterol acyl transferase (L-CAT) playing an important role in the cholesterol transport. ${ }^{34}$

TGs can act as an independent risk factor for CHD. It is also called as ugly fat. ${ }^{35}$ The reduction in the TGs and increase in the HDL cholesterol found in our study could be due to hydrolysis of TG rich lipoproteins that simultaneously replace intramuscular fat used during pranayama and yogic practices. ${ }^{36}$ It seems quite probable that increased physical activity leads to lower plasma TG concentration and ultimately increased plasma HDL cholesterol. Physical activity and HDL appear to be linked via HDL's role in TG metabolism. ${ }^{36}$ The psychosomatic stress or the oxidative stress causes decreased HDL levels due to its increased utilization in scavenging the free radicals. ${ }^{37}$ The subjects who are already having the disease i.e. Group III may be under more stress which is relieved after the yoga therapy and hence the concentration of HDL increased significantly in these groups after yoga. Group II and I, which showed increasing levels in the HDL, may have significant increase with further continuation of yoga.

There are very few studies showing the consistent effects of yoga on LDL. Prasad KKK et $\mathbf{a l}^{36}$ showed significant reduction in TGs, VLDL and significant elevation of HDL cholesterol in men after yoga training while in women there was significant decrease in serum cholesterol TG, LDL and VLDL. The results were attributed to the gender difference by the author. Bijalani et $\mathbf{a l}^{38}$ had found significant decrease in all components of lipid profile after yoga except HDL which was elevated significantly. Moderate physical activity and not severe one can reduce the LDL cholesterol. Yoga postures that are equivalent to moderate exercise caused decreased LDL .Present study showed changes in the VLDL levels parallel to TG levels in all the three groups. The total cholesterol (or LDL cholesterol) to HDL cholesterol ratio represents a simple, efficient way to help estimate coronary disease risk. The present study found higher TC/HDL ratio in Group II, III as compared to Group I at baseline. Ninety days of yoga therapy resulted in significant reduction $(\mathrm{p}<0.01)$ in Group I, II and 
III [Table 4-6]. Thus yoga causes reduction in the risk for CHD in these subjects. Similar to TC/HDL ratio ,the LDL/HDL ratio was also found to be significantly decreased ( $<<0.01$ ) in Group I, II and III , further confirming the reduction in the risk of CHD after yoga. [Table 4-6] In hypertension whether newly diagnosed or already diagnosed, there is restoration of the altered parameters towards normal.We can conclude that yoga is beneficial not only in normal persons but also in newly diagnosed stage 1 hypertensive subjects or previously diagnosed hypertensives.

\section{Bibliography}

[1]. Williams GH. Hypertensive vascular disease. In: Braunwald E, Fauci AS, Kasper DL, Hauser SL, Longo DL, Jameson JL, editors. Harrison's principles of internal medicine. 15th ed. New York: McGraw-Hill; 2001. P. 1414-1430.

[2]. Powers AC. Diabetes mellitus. In: Braunwald E, Fauci AS, Kasper DL, Hauser SL, Longo DL, Jameson JL, editors. Harrison's principles of internal medicine. vol II, 15th ed. New York: McGraw-Hill; 2001. P.2109-2137.

[3]. Hypertension study group. Prevalence, awareness, treatment and control of hypertension among the elderly in Bangladesh and India: a multicentre study. Bull WHO 2001; 79(6): 490-500.

[4]. Whitworth JA. 2003 World Health Organization (WHO)/International society of Hypertension (ISH) statement on management of hypertension. J hypertens 2003; 21(11) 1983-92.

[5]. Ferro A, Gilbert R, Krum H. Importance of renin in blood pressure regulation and therapeutic potential of renin inhibition. Int J Clin Pract 2006; 60(5): 577-581.

[6]. Gress TW, Nieto FJ, Shahar E, Wofford MR, Brancati FL. Hypertension and antihypertensive therapy as risk factors for type 2 Diabetes Mellitus. NEJM 2000; 342(13): 905-912.

[7]. Wasserman LI, Trifonova EA, Diabetes mellitus as a model of psychosomatic and somatopsychic interrelationships.The Spanish Journal of Psychology 2006;9(1):75-85.

[8]. Wang TJ, Vasan RS. Epidemiology of uncontrolled hypertension in the United States.Circulation 2005; 112:1651-1662.

[9]. Mamtani R. Ayurveda and yoga in cardiovascular diseases. Cardiol Rev 2005; 13(3): 155-162.

[10]. Damodaran A, Malathi A, Patil N, Shah N, Suryavanshi, Marathe S. Therapeutic potential of yoga practices in modifying cardiovascular risk profile in middle aged men and women. JAPI 2002; 50: 633-640.

[11]. Bharshankar JR, Bharshankar RN, Deshpande VN, Kaore SB, Gosavi GB. Effect of yoga on cardiovascular system in subjects above 40 years. IJPP 2003; 47(2): 202-206.

[12]. Madanmohan, Udupa K, Bhavanani AB, Shatapathy CC, Sahai A. Modulation of cardiovascular response to exercise by yoga training. IJPP 2004; 48(4): 461-465.

[13]. Vijayalakshmi P, Madanmohan, Bhavanani AB, Patil A, Kumar Babu P. Modulation of stress induced by isometric handgrip test in hypertensive patients following yogic relaxation training. IJPP 2004; 48(1): 59-64.

[14]. Singh S, Malhotra V, Singh KP, Madhu SV, Tandon OP. Role of yoga in modifying certain cardiovascular functions in Type 2 diabetic patients. JAPI 2004; 52: 203-206.

[15]. Khare KC, Sanghvi VC, Surana DC. Haematological, biochemical and ventilatory responses to the practice of yoga in adults. Yoga Mimamsa 1989; 28(1): 65-72.

[16]. Frumkin K, Nathan RJ, Prout MF, Cohen MC. Nonpharmacologic control of essential hypertension in man: a critical review of the experimental literature. Psychosom Med 1978; 40(4): 294-320.

[17]. Guyton AC, Hall JE. Heart muscle: the heart as a pump and the function of the heart valves. In: Text book of medical physiology. 11th ed. Philadelphia: saunders; 2006. p. 103-115.

[18]. Gupta N, Khera S, Vempati RP, Sharma R, Bijlani RL. Effect of yoga based lifestyle intervention on state and trait anxiety. IJPP 2006; 50(1): 41-47.

[19]. Vyas R, Dikshit N. Effect of meditation on respiratory system, cardiovascular system and lipid profile. IJPP 2002; 46(4): 487-491.

[20]. Murugesan R, Govindarajulu N, Bera TK. Effect of selected yogic practices on the management of hypertension. IJPP 2000; 44(2): 207-210.

[21]. Dhameja,Kanupriya;Singh,Savita;Mustafa,M.D;Singh,K.P;Banerjee Basu Dev ;Agarwal,Mukul ;Ahmed,Rafat S .Therapeutic effect of yoga in patients with hypertension with references to GST Gene polymorphism.Journal of Alternative and Comlementary Medicine March 2013;19(3):243

[22]. 22.Jayaram Gadham,Shrikant Sajja,V Rooha. Effect of yoga on obesity,hypertension and lipid profile.Int J Res Med Sci 2015;2(5):1061-1065

[23]. Dr.Mohd.Noor Jahan Begum,Dr.K Kamal Chand .To evaluate the effect of yoga on moderate degree hypertension and lipid profile.NJIRM2013;4(3):109-114

[24]. Selvamurthy W, Sridharan K, Ray US, Tiwary RS, Hegde KS, Radhakrishan U, Sinha KC. A new physiological approach to control essential hypertension. IJPP 1998; 42(2): 205-213.

[25]. Ilse L, VanGaal LF. Overweight, obesity and blood pressure: the effects of modest weight reduction. Obesity research 2000; 8(3): 270-278.

[26]. Zizek B, Poredos P. Insulin resistance adds to endothelial dysfunction in hypertensive patients and in normotensive offsprings of subjects with essential hypertension. J Intern Med 2001; 249: 189-197.

[27]. Deepak KK. Neurophysiological mechanisms of induction of meditation: A hypothetico-deductive approach. IJPP 2002; 46(2): 136-158.

[28]. Haider AW, Larson MG, Franklin SS, Levy D. Systolic blood pressure, diastolic blood pressure and pulse pressure as predictors of risk for congestive heart failure in the Framingham Heart study. Ann Inter Med 2003; 138(1): 10-16.

[29]. Verdecchia P, Schillaci G, Reboldi G, Franklin SS, Porcellati C. Clinical investigation and reports: Different prognostic impact of hour mean blood pressure and pulse pressure on stroke and coronary artery disease in essential hypertension. Circulation 2001; 103: 2579 .

[30]. Verdecchia P, Reboldi G, Angeli F, Gattobigio R, Borgioni C, Filippucci L, Poeta F, Porcellati C. Prognostic value of lipoprotein fractions in essential hypertension. Blood Press 2004; 13(n $\left.\mathrm{n}^{0} 15\right)$ : 295-303.

[31]. Khare KC, Jain D. Effect of yoga on plasma glucose and serum fructosamine level in NIDDM. Yoga Mimamsa 1999; 33(4): 1-9.

[32]. Bhagal RS, Bhat SG, Kulkarni DD, Bera TK. Effect of meditation, similar to the one mentioned in Shiv Samhita, preceded by Omkar on reaction time and selected biochemical and hematological parameters: A pilot study. Yoga Mimamsa 1999; 33(4): 10-28.

[33]. Mishra KK, Pandey HP. A study on physiological changes in essential hypertension and rheumatoid arthritis with reference to the levels of cortisol, blood glucose, triglycerides and cholesterol. IJPP 1995; 39(1): 68-70. 
[34]. Simko V, Kelley RE. Physical exercise modifies the effect of high cholesterol-sucrose feeding in the rat. Eur J Appl Physiol Occup Physiol 1979; 40(3): 145-53.

[35]. Hokanson JE, Austin MA. Plasma triglyceride level is a risk factor for cardiovascular disease independent of high density lipoprotein cholesterol level: a meta-analysis of population-based prospective studies. J Cardiovasc Risk 1996;3(2):213-219.

[36]. Prasad KVV, Sunita M, Raju PS, Reddy MV, Sahay BK, Murthy KJY. Impact of pranayama and yoga on lipid profile in normal healthy volunteers. JEP online 2006; 9(1): 1-6.

[37]. Tomas M, Latorre G, Senti M, Marrugat J. The antioxidant function of High Density Lipoproteins: A new paradigm in atherosclerosis. Rev Esp Cardiol 2004; 57(6): 557-569.

[38]. Bijlani RL, Vempati RP, Yadav RK, Ray RB, Gupta V, Sharma R, Mehta N, Mahapatra SC. A brief but comprehensive lifestyle education programme based on yoga reduces risk factors for cardiovascular diseases and diabetes mellitus. J Altern Complement Med 2005; 11(2): 267-74. 